\title{
Improved Fuzzy Evaluation Model of Military Supply Chain Performance Based on Variable Weight
}

\author{
Heng Zhang, Qiang Lin, Zhi guo Qu \& Kun Zhang \\ Air Force Early Warning Academy, Wuhan, 430019, China
}

Keywords: military supply chain, performance evaluation, fuzzy evaluating, variable weight.

\begin{abstract}
According to the characteristics of military supply chain, we design the indicator of performance evaluation based on the key factors of supply chain strategy in this paper. When talking about estimating performance evaluation, in order to materialize the punitive or stimulant request that decision-maker performs towards decision-making factors, but constant weight synthesis method can't fulfill the request, so an improved fuzzy evaluating model based on hierarchy variable weight is put forward.
\end{abstract}

\section{Introduction}

Military supply chain is a new kind of logistics support mode, adapting to the needs of the development of the information war and network war [1]. It puts together purchase, stock, transportation and ultimately armies, which brings the advantages of the supply chain into full play and gains the maximum benefits of the supply chain. In order to evaluate the integrated effect of military supply chain and improve the performance of military supply chain, reasonable evaluation methods and appropriate evaluation indicators should be adopted to get the feedback information timely in the process of military supply chain management[2].

Traditional performance evaluation methods of supply chain include linear weighted method, multi-objective fuzzy evaluation, probability and statistics based ways, etc [3], which give reasonable evaluation results in most circumstances. However, two main drawbacks lie in the traditional methods: the value setting of indicators and the weighting of each indicator. Generally, the values of most indicators for evaluating the performance of the military supply chain are hard to set quantitatively. Moreover, the lower value of one single indicator will greatly reduce the overall performance whereas the higher value of one single indicator will not necessarily make the overall performance increased significantly. Therefore, the indicator's weight should change with the evaluation value where penalty weight should be larger than the awarding value. In this paper, a fuzzy evaluating model based on variable weight and corresponding indicators concerning three key factors of military supply chain strategy are proposed.

\section{The indicator system of performance evaluation}

In order to evaluate the performance of supply chain, many scholars have proposed various evaluation indicator systems. These indicator systems can be largely divided into three categories: SCOR, balanced score card and ROF (resource, output and flexible) [4,5]. However, most of these index systems is introduced based on enterprise supply chain and may not apply to the military supply chain. The indicator system of military supply chain performance evaluation must establish according to its own characteristics [6].

By reviewing international and domestic supply chain performance evaluation index system, we list out the key factors (resource, output, and the flexible) of supply chain strategy on which the indicator of performance evaluation are based, and break them down into detailed sub-items. Based on these detailed sub-items, we design our performance evaluation indicator system (see Fig.1) according to the characteristics of military supply chain. 


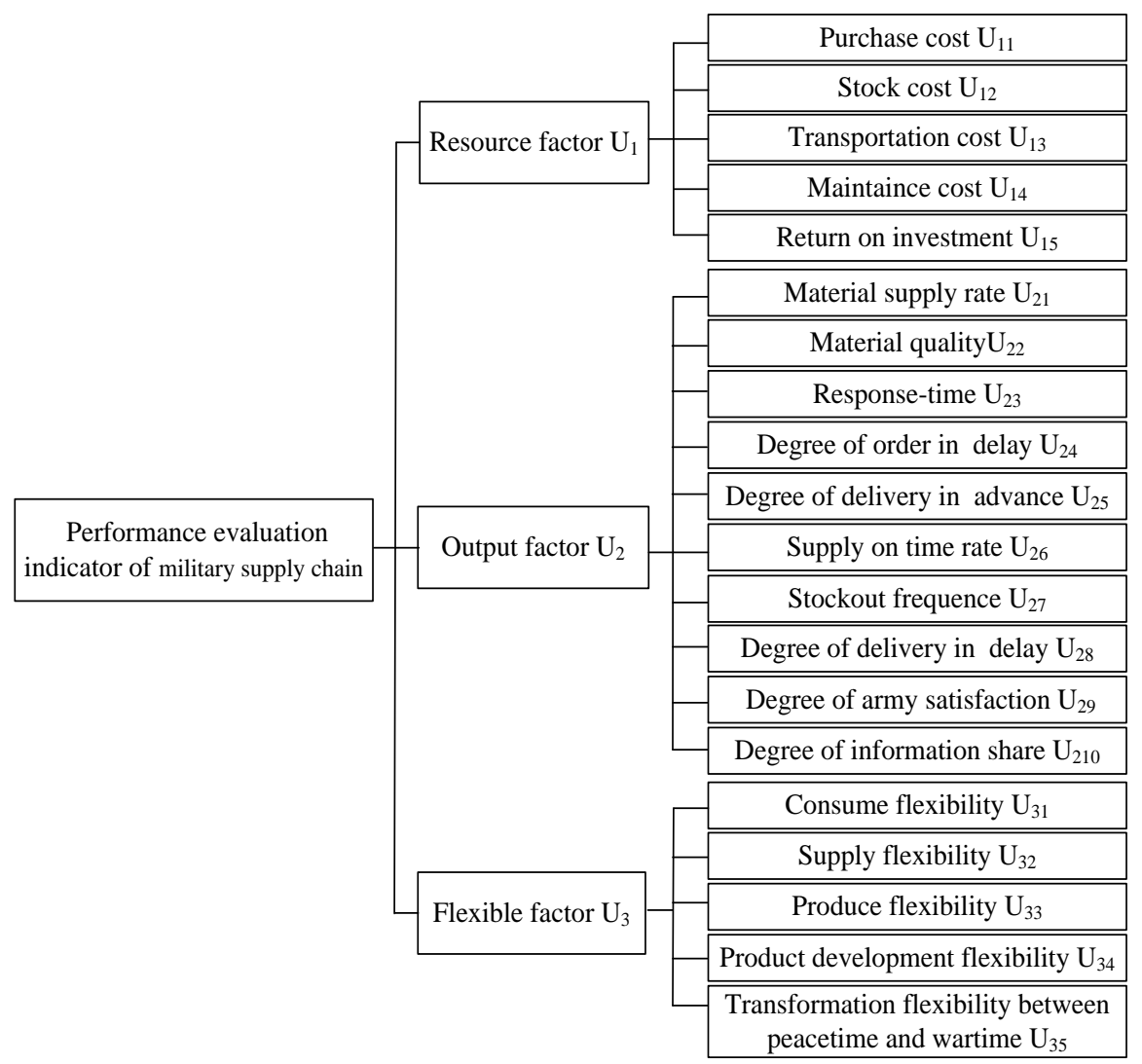

Fig.1: The indicator system of military supply chain performance evaluation

\section{The fuzzy evaluation model}

The indicator of military supply chain performance evaluation has two hierarchies. Let the first hierarchy indicator be $\left(\phi_{1}, \phi_{2}, \cdots, \phi_{n}\right)$, then the second hierarchy indicator $q_{j}$ of $\phi_{i}$ are defined as $\left(\phi_{i 1}, \phi_{i 2}, \cdots, \phi_{i q_{j}}\right)$.The weights and the factor evaluation matrices of first and second hierarchy indicators are denoted as $\omega_{i}, \omega_{i j}$ and X, $X^{\prime}$ respectively.

The fuzzy evaluation model calculates the value of performance evaluation, sorting into orders the performance of supply chain. The basic steps are as follows:

\section{The determination of indicator weights}

Construct the decision matrix of every hierarchy indicators, calculate the maximal eigenvalue and its eigenvectors and educe the relative weights of every hierarchy indicators[7]. Analyze the consistency and error in the decision matrix and reduce the first weights ${ }^{\omega_{i}}$ and the second grades indicators $\omega_{i j}$.

\section{The single factor fuzzy evaluation}

Construct the factors and evaluation sets of every hierarchy indicators[8]. Set up performance evaluation team and judge indicators. Educe the factor evaluation matrixes of second hierarchy indicators $X^{\prime}$.

\section{The fuzzy comprehensive evaluation}

Educe $X_{i}$ and $\mathrm{V}$ accordingg to Eq. 1 and Eq. 2 respectively. Ordering the performancee of supply chain according to the value of $\mathrm{V}$.

$$
\begin{gathered}
X_{i}=\sum_{j=1}^{q_{i}} \omega_{i j} \cdot X_{i}^{\prime} \quad i=1,2, \cdots, n \\
V=\sum_{i=1}^{n} \omega_{i} \cdot X_{i}
\end{gathered}
$$




\section{The fuzzy evaluation model based on hierarchy variable weight}

The principle of variable weight is the indicators' weight varies with the indicators' value, in order to make weight can better reflect the corresponding factors role in decision making[9].

\section{The establishment of decision model}

Because $\phi_{1}, \phi_{2}, \cdots, \phi_{n}$ mutual independence, we may assume that the value ${ }^{y_{j}}$ of $\phi_{j}$ is the evaluate value of $\phi_{j 1}, \phi_{j 2}, \cdots, \phi_{j q_{j}}, X^{\prime}=\left(x_{j 1}, x_{j 2}, \cdots, x_{j q_{j}}\right)$ is the factors' state vector, $\omega_{j}=\left(\omega_{j 1}, \omega_{j 2}, \cdots, \omega_{j q}\right)$ is constant weight vector, $S_{j}\left(x_{j 1}, x_{j 2}, \cdots, x_{j q_{j}}\right)=\left(S_{j 1}\left(x_{j 1}, x_{j 2}, \cdots, x_{j q_{j}}\right), \cdots, S_{j q_{j}}\left(x_{j 1}, x_{j 2}, \cdots, x_{j q_{j}}\right)\right)$ is variable weight vector. Using variable weight evaluation[10], we have

$$
y_{j}=\sum_{i=1}^{q_{j}} \omega_{j i}^{\prime}\left(x_{j 1}, x_{j 2}, \cdots, x_{j q_{j}}\right) x_{j i}
$$

Where,

$$
\omega_{j i}^{\prime}\left(x_{j 1}, x_{j 2}, \cdots, x_{j q_{j}}\right)=\frac{\omega_{j i} S_{j i}\left(x_{j 1}, x_{j 2}, \cdots, x_{j q_{j}}\right)}{\sum_{k=1}^{q_{j}} \omega_{j i} S_{j k}\left(x_{j 1}, x_{j 2}, \cdots, x_{j q_{j}}\right)}
$$

We use variable weight method to evaluate $Y=\left(y_{1}, y_{2}, \cdots, y_{n}\right)$. We assume $\omega=\left(\omega_{1}, \omega_{2}, \cdots, \omega_{n}\right)$ is the constant weight vector, $S\left(y_{1}, y_{2}, \cdots, y_{n}\right)=\left(S_{1}\left(y_{1}, y_{2}, \cdots, y_{n}\right), \cdots, S_{n}\left(y_{1}, y_{2}, \cdots, y_{n}\right)\right)$ is the variable weight vector. We obtain the decision value

$$
V_{n}\left(y_{1}, y_{2}, \cdots, y_{n}\right)=\sum_{j=1}^{n} \omega_{j}^{\prime}\left(y_{1}, y_{2}, \cdots, y_{n}\right) y_{j}
$$

Where,

$$
\omega_{j}^{\prime}\left(y_{1}, y_{2}, \cdots, y_{n}\right)=\frac{\omega_{j} S_{j}\left(y_{1}, y_{2}, \cdots, y_{n}\right)}{\sum_{i=1}^{m} \omega_{i} S_{i}\left(y_{1}, y_{2}, \cdots, y_{n}\right)}
$$

According to the value of $\mathrm{Vn}$. we can obtain the comprehensive evaluation results. If there are two grades above structure of the indicator system, we can also refer to the above method to calculate.

\section{The determination of mapping function}

Mapping function determines the indicator weight of the extent of punishment and reward. Because the actual situation of military supply chain performance evaluation demands punishment range should be larger than the reward [11], we determine the following mapping function.

$$
S_{j}(x)=\left\{\begin{array}{c}
b^{\frac{1}{m_{i} \omega_{j i}}}+d \quad x_{j} \in[0, a] \\
{\left[\frac{b\left(b-x_{j}\right)}{b-a}\right]^{\frac{1}{m_{i} \omega_{j i}}}+d \quad x_{j} \in[a, b]} \\
d \quad x_{j} \in[b, c] \\
{\left[e \cdot \frac{b\left(x_{j}-c\right)}{1-c}\right]^{\frac{1}{m_{i} \omega_{j i}}}+d \quad x_{j} \in[c, 1]}
\end{array}\right.
$$

Where $m_{i}$ is the number of indicators, $\omega_{j i}$ is the constant weight vector of $x_{j}, x_{j}, a, b, c, d, e \in[0,1], a$ is the negative threshold, $b$ is the pass threshold, $c$ is the reward threshold, $d$ is the adjustment extent, $e$ is the extent rate of reward and punishment. According to the actual situation of the military supply chain, we apply these values: $\mathrm{a}=0.3, \mathrm{~b}=0.6, \mathrm{c}=0.9, \mathrm{~d}=0.2$, $\mathrm{e}=0.75$. 


\section{Examples of evaluation}

Using the analytic hierarchy process (AHP), experts determine the constant weights of indicators, investigate four military supply chain (A1, A2, A3, A4) each secondary grade indicators of single factor valuation. The result of constant weights and single factor valuation is shown in table 1.

Table 1: The data of constant weight and single factor evaluation

\begin{tabular}{|c|c|c|c|c|c|}
\hline \multirow{3}{*}{$\begin{array}{c}\text { First } \\
\text { indictors } \\
\text { weights }\end{array}$} & \multirow{3}{*}{$\begin{array}{c}\text { Secondary } \\
\text { indicators } \\
\text { weights }\end{array}$} & \multicolumn{4}{|c|}{ The single factor evaluation data of } \\
\hline & & & & $-\ldots$ & \\
\hline & & A1 & A2 & A3 & A4 \\
\hline \multirow{5}{*}{$\begin{array}{c}\mathrm{U}_{1} \\
(0.383)\end{array}$} & $\mathrm{U}_{11}(0.305$ & 0.800 & 0.600 & 0.990 & 0.602 \\
\hline & $\mathrm{U}_{12}(0.164$ & 0.802 & 0.802 & 0.810 & 0.600 \\
\hline & $\mathrm{U}_{13}(0.240$ & 0.801 & 0.800 & 0.990 & 0.402 \\
\hline & $\mathrm{U}_{14}(0.138$ & 0.801 & 0.803 & 0.981 & 0.605 \\
\hline & $\mathrm{U}_{15}(0.152$ & 0.989 & 0.605 & 0.983 & 0.605 \\
\hline \multirow{10}{*}{$\begin{array}{c}\mathrm{U}_{2} \\
(0.411)\end{array}$} & $\mathrm{U}_{21}(0.074$ & 0.402 & 0.801 & 0.997 & 0.800 \\
\hline & $\mathrm{U}_{22}(0.158$ & 0.800 & 0.997 & 0.188 & 0.700 \\
\hline & $\mathrm{U}_{23}(0.046$ & 0.989 & 0.987 & 0.978 & 0.802 \\
\hline & $\mathrm{U}_{24}(0.051$ & 0.259 & 0.262 & 0.463 & 0.295 \\
\hline & $\mathrm{U}_{25}(0.041$ & 0.963 & 0.597 & 0.498 & 0.668 \\
\hline & $\mathrm{U}_{26}(0.108$ & 0.117 & 0.221 & 0.218 & 0.499 \\
\hline & $\mathrm{U}_{27}(0.126$ & 0.168 & 0.048 & 0.063 & 0.076 \\
\hline & $\mathrm{U}_{28}(0.162$ & 0.527 & 0.472 & 0.469 & 0.486 \\
\hline & $\mathrm{U}_{29}(0.183$ & 0.871 & 0.862 & 0.882 & 0.901 \\
\hline & $\mathrm{U}_{210}(0.05$ & 0.344 & 0.592 & 0.492 & 0.119 \\
\hline \multirow{5}{*}{$\begin{array}{c}\mathrm{U}_{3} \\
(0.206)\end{array}$} & $\mathrm{U}_{31}(0.118$ & 0.527 & 0.965 & 0.585 & 0.630 \\
\hline & $\mathrm{U}_{32}(0.380$ & 0.355 & 0.953 & 0.962 & 0.728 \\
\hline & $\mathrm{U}_{33}(0.240$ & 0.396 & 0.963 & 0.820 & 0.712 \\
\hline & $\mathrm{U}_{34}(0.145$ & 0.477 & 0.992 & 0.654 & 0.267 \\
\hline & $\mathrm{U}_{35}(0.117$ & 0.826 & 0.862 & 0.876 & 0.965 \\
\hline
\end{tabular}

\section{Fuzzy evaluation}

According to the Eq.1, we can evaluate the secondary indicators. where

$$
\begin{aligned}
X_{1} & =\left(\omega_{11}, \omega_{12}, \omega_{13}, \omega_{14}, \omega_{15}\right) \cdot\left(x_{11}, x_{12}, X_{13}, X_{14}, x_{15}\right)^{T} \\
& =(0.305,0.164,0.240,0.138,0.152)(0.8,0.802,0.801,0.801,0.989)^{T} \\
& =0.8296
\end{aligned}
$$

Similarly, we can get the secondary evaluation matrix $X$. By substituting $X$ into the Eq.2, we can obtain

$$
V=(0.6383,0.7123,0.7377,0.5822)
$$

We can obtain $V_{3}>V_{2}>V_{1}>V_{4}$ form the result. Thus, in the four military supply chain, the highest performance is A3, the order of rest supply chain' performance is A2, A1 and A4 in turn.

Hierarchical fuzzy evaluation model of variable weight.

We calculate the performance evaluation of A3 as an example.

The variable weight value of $\mathrm{U}_{11}, \mathrm{U}_{12}, \mathrm{U}_{13}, \mathrm{U}_{14}, \mathrm{U}_{15}$ in A3' performance evaluation is

$$
\left(\omega_{11}^{\prime}, \omega_{12}^{\prime}, \omega_{13}^{\prime}, \omega_{14}^{\prime}, \omega_{15}^{\prime}\right)=(0.4181,0.0590,0.2897,0.1072,0.1310)
$$


and so

$$
\begin{aligned}
y_{1}^{3} & =\left(\omega_{11}^{\prime}, \omega_{12}^{\prime}, \omega_{13}^{\prime}, \omega_{14}^{\prime}, \omega_{15}^{\prime}\right)\left(x_{11}^{3}, x_{12}^{3}, x_{13}^{3}, x_{14}^{3}, x_{15}^{3}\right)^{T} \\
& =(0.4181,0.059,0.2897,0.1072,0.131)(0.99,0.81,0.99,0.981,0.983)^{T}=0.9775
\end{aligned}
$$

Similarly, we can obtain $\left(y_{1}^{3}, y_{2}^{3}, y_{3}^{3}\right)=(0.9775,0.3565,0.8940)$

The variable weight value of $\mathrm{U}_{1}, \mathrm{U}_{2}, \mathrm{U}_{3}$ in $A 3^{\prime}$ ' performance evaluation is

$$
\left(\omega_{1}^{\prime}, \omega_{2}^{\prime}, \omega_{3}^{\prime}\right)=(0.3944,0.5348,0.0707)
$$

and so

$$
\begin{aligned}
V_{3}^{\prime} & =\left(\omega_{1}^{\prime}, \omega_{2}^{\prime}, \omega_{3}^{\prime}\right)\left(y_{1}^{3}, y_{2}^{3}, y_{3}^{3}\right)^{T} \\
& =(0.3944,0.5348,0.0707)(0.9775,0.3565,0.894)^{T} \\
& =0.6394
\end{aligned}
$$

Similarly, we can obtain $\left(V_{1}^{\prime}, V_{2}^{\prime}, V_{3}^{\prime}, V_{4}^{\prime}\right)=(0.4790,0.6453,0.6394,0.4671), V_{2}^{\prime}>V_{3}^{\prime}>V_{1}^{\prime}>V_{4}^{\prime}$. Compared with constant weights of fuzzy evaluation, the performance of A3 decreases more than other supply chain. The main reason is that the U22 evaluation value of A3 is much lower than other supply chains, suggesting that the hierarchy fuzzy evaluation model of variable weight can realize the desired effect.

\section{Conclusions}

The ultimate goal of military supply chain performance evaluation is to optimize the whole process of supply chain which definitely will reduce the supply time and improve the efficiency of support. In this paper, we designs the indicator of performance evaluation based on the key factors of supply chain strategy, where we combine the fuzzy evaluation with hierarchy variable weight theory to do the performance calculation procedure. Experimental results on a real example demonstrate that our model is more scientific. Moreover, the model proposed in our paper is flexible and thus can be applied to other supply chain performance evaluation.

\section{References}

[1] Wang Jin fa, Li Li. Military Supply Chain Management, Beijing: National Defence University Press, 2004.

[2] Chan, F T S, Qi, H J. A fuzzy basis channel-spanning performance measurement method for supp chain management. Proceedings of the Institution of Mechanical Engineers-PartBEngineering Manufacture, 216(8),pp.1155-1167,2002.

[3] Bullinger $\mathrm{H}$, Kuhner $\mathrm{M}$ et al. Analyzing supply chain performance using a balanced measurement method. Int. J. Production Research, 40(15),pp.3533-3543,2002.

[4] Dominique Estampe. A framework for analysing supply chain performance evaluation models. Int. J. Production Economic, 11,pp.27-35,2010.

[5] Narasimhan R, Talluri S, Mendez D. Supplier evaluation and rationalization via data envelopment analysis: an empirical examination. The Journal of Supply Chain Management, 2001, 37(1),pp.28-37,2001.

[6] Zhao Yong gang, Sheng Fu li et al. Risk Evaluation of Military Logistics Supply Chains Based on Fuzzy Synthetic Evaluation Model. Academy of Military Transportation, 4, pp.76-78,2009.

[7] Shi Zhong zhi,Wang Wen jie. Artificial intelligence, Beijing: National Defence Industry Press,2007.

[8] F. T. S. CHAN. Interactive selection model for supplier selection process: an analytical hierarchy process approach. International Journal of Production Research, 2003, 41(15),pp.3549-3579,2003.

[9] Tam C Y, Tummala V M. An application of the AHP in vendor selection of a telecommunications system. International Journal of Management Science, 29(2),pp.171$182,2001$. 
[10] A Gunasekaram, C Patel, E Tirtiroglu. Performance measures and metrics in a supply chain environment. International Journal of Operations and Production Management, 21(12),pp.7187,2001.

[11] Adel El-Ba M. Fuzzy performance measurement of a supply chain in manufacturing companies. Expert Systems with Applications, 38(6),pp.6681-6688,2011. 